\title{
Effect of complexing salt on conductivity of PVC/PEO polymer blend electrolytes
}

\author{
S RAJENDRAN*, RAVI SHANKER BABU ${ }^{\dagger}$ and M USHA RANI ${ }^{\dagger}$ \\ Department of Physics, Alagappa University, Karaikudi 630 003, India \\ ${ }^{\dagger}$ School of Advanced Studies, VIT University, Vellore 632 014, India
}

MS received 28 February 2008

\begin{abstract}
Solid polymer electrolyte membrane comprising poly(vinyl chloride) (PVC), poly(ehylene oxide) (PEO) and different lithium salts $\left(\mathrm{LiClO}_{4}, \mathrm{LiBF}_{4}\right.$ and $\left.\mathrm{LiCF}_{3} \mathrm{SO}_{3}\right)$ were prepared by the solution casting technique. The effect of complexing salt on the ionic conductivity of the PVC/PEO host polymer is discussed. Solid polymer electrolyte films were characterized by X-ray diffraction, FTIR spectroscopy, TG/DTA and ac impedance spectroscopic studies. The conductivity studies of these solid polymer electrolyte (SPE) films are carried out as a function of frequency at various temperatures ranging from $302 \mathrm{~K}$ to $353 \mathrm{~K}$. The maximum room temperature ionic conductivity is found to be $0.079 \times 10^{-4} \mathrm{~S} \mathrm{~cm}^{-1}$ for the film containing $\mathrm{LiBF}_{4}$ as the complexing salt. The temperature dependence of the conductivity of polymer electrolyte films seems to obey the Vogel-TammanFulcher (VTF) relation.
\end{abstract}

Keywords. Solid polymer electrolytes; Li-ion conduction; XRD; FTIR; TG/DTA.

\section{Introduction}

A driving force in the investigation and development of new polymeric electrolytes is the possibility of their application in various electrochemical devices (MacCallum and Vincent 1987; Vincent 1987; Gray 1991; Scrosati and Neat 1993; Bruce 1995). Much effort has gone into the enhancement of the ionic conductivity at ambient and sub-ambient temperatures of polyether-based electrolytes - the most intensively studied systems. Novel polymeric ionic conductors such as networks (Cheradame and Lee Nest 1987), gels (Abraham 1993), blends (Inganas 1988) and composites (Croce et al 1998) have been synthesized and their structure conductivity characteristics have been discussed. The electrochemical stability of polymeric electrolytes in contact with alkali metal electrodes primarily lithium, and the compatibility of these electrolytes with electrode materials, is crucial in electrochemical devices (Kelley et al 1984; Scrosati 1987; Fautex 1988; Croce et al 1990; Capuano et al 1991; Borkowska et al 1993; Appetecchi et al 1995). The resistance of passive layer formed between lithium electrode and polymeric electrolyte increases with time, and the uncontrolled passivation phenomena affect the cyclability of lithium electrodes, and therefore the entire lithium battery (Scrosati et al 1993). It is presumed that the nature of this layer depends largely on the composition and purity

\footnotetext{
*Author for correspondence (sraj54@yahoo.com)
}

of the electrolyte. The layer, having properties of solid lithium ionic conductor with a high electrical resistance, acts as a solid phase between the lithium and the electrolyte. Scrosati and others (Croce et al 1990; Capuano et al 1991; Scrosati 1993) demonstrated that the addition of inorganic fillers, such as $\mathrm{LiAlO}_{2}$ or zeolites, improves electrode electrolyte compatibility and reduces the passivation phenomena and also Yamamoto and co-workers reported an increase of the electrical conductivity, especially at lower temperature, and a decrease of the interfacial resistance between the lithium anode and the polymer electrolyte (Sun et al 2000) by the addition of ferroelectric material, $\mathrm{BaTiO}_{3}$. Moreover, they investigated the particle size effect of $\mathrm{BaTiO}_{3}$ on the ionic conduction of composite polymer electrolyte, and large particle size $\mathrm{BaTiO}_{3}$ would increase the salt dissociation because of ferroelectric domains developed in the ceramics (Capiglia et al 2002; Takeuchi et al 2002). This has been attributed to the effect of such fillers on polymer impurities (e.g. moisture or low-molecular-weight volatile solvents), which are suspected to react with lithium leading to the formation and growth of these passive layers. In addition to the composite polymer, a blend-based polymer electrolyte, composed of two conductive components and lithium salts, is another example with favourable electrical properties, and, for example, there are (PEO-poly[bis (methoxyethoxyethoxide) phosphazene])- $\mathrm{LiN}\left(\mathrm{CF}_{3} \mathrm{SO}_{2}\right)$, PEO-poly[bis(triethyleneglycolbenzoate] capped with an acetyl group - $\mathrm{LiN}\left(\mathrm{CF}_{3} \mathrm{SO}_{2}\right)_{2}$ (Abraham 1991; Wen et al 2000; Itoh et al 2001) and poly(ethylene oxide) (PEO)- 
$\mathrm{LiClO}_{4}$ electrolytes with various methacrylic and acrylic polymers used as additives (Borkowska et al 1993), which limits the growth of resistance of passive layers. One conductive component in the blend-based polymer electrolytes acts as a plasticizer to reduce the nonconductive crystalline phase of PEO, leading to an increase in the ionic conductivity at low temperatures.

Since the conductivity of poly(ethylene oxide) salt complex was reported by Fenton et al (1973), researchers were ardent in finding a solution to these PEO-based polymer electrolytes that possessed poor conductivity at low temperatures, later Armand and his collaborators (1979) reported the practical application of PEO for batteries. However, research efforts are still underway to increase the ionic conductivity (Balleard et al 1990; Dobrowski et al 1991) in cojunction with its thermal stability (Huang et al 1996).

Based on the conception (Borkowska et al 1993), in the present work an attempt has been made to prepare PVCPEO polymer-blend electrolytes bereft of plasticizers, which could give higher ionic conductivity and good electrode electrolyte contact (reduced passive layer), with good thermal stability. PVC has been used to blend with PEO because of its commercial availability, inexpensiveness and its widespread use is attributed mainly to the presence of lone pair electrons at the chlorine atom where inorganic salts can be solvated.

The present paper reports on the effect of complexing salt upon the conductivity of PVC-PEO-blended polymer electrolyte. The blend optimization of PVC-PEO has been reported elsewhere (Rajendran et al 2007). The polymer electrolytes prepared were subjected to XRD, FTIR for structural elucidation, TG/DTA for thermal stability and a.c. impedance technique for conductivity measurements.

\section{Experimental}

Poly(vinyl chloride) (PVC) (average molecular weight $1.5 \times 10^{5}$ ) and poly(ethylene oxide) (PEO) (average molecular weight $1 \times 10^{5}$ ) purchased from Aldrich, USA, were dried at $100^{\circ} \mathrm{C}$ and $45^{\circ} \mathrm{C}$, respectively, for $5 \mathrm{~h}$; salts $\mathrm{LiClO}_{4}, \mathrm{LiBF}_{4}$ and $\mathrm{LiCF}_{3} \mathrm{SO}_{3}$ procured from Aldrich, USA, was dried at $70^{\circ} \mathrm{C}$ under vacuum for $24 \mathrm{~h}$. The electrolyte thin films were prepared by solution casting technique. Appropriate quantities of PVC, PEO and Li salts were dissolved in predistilled THF and stirred for about $10 \mathrm{~h}$ at room temperature and then at $45^{\circ} \mathrm{C}$ for $2 \mathrm{~h}$ before casting the films on glass plates. The films were dried in vacuum oven at $303 \mathrm{~K}$ at a pressure of $10^{-3}$ Torr for $5 \mathrm{~h}$. The phase analysis of the polymer electrolyte was performed with XRD [Bruker (D8 Advance)] diffractometer at room temperature. The FTIR spectrum in the range $4000-400 \mathrm{~cm}^{-1}$ was recorded using Jasco FTIR 460 plus (Japan) spectrophotometer.
Conductivity measurements were carried out on the thin films using Keithley LCZ meter (model 3330) with a signal amplitude of $10 \mathrm{mV}$ in the frequency range $40 \mathrm{~Hz}-$ $100 \mathrm{kHz}$. The variation of conductivity with temperature is recorded in the temperature range between $303-353 \mathrm{~K}$. The thermal stability is ascertained from the TG/DTA conducted on the film using PERKIN ELMER (pyres diamond) TG/DTA instrument with a heating rate of $10^{\circ} \mathrm{C} / \mathrm{min}$.

\section{Results and discussion}

\subsection{XRD analysis}

XRD studies provided a wide range of information on crystal structure, orientation, crystallinity and phase changes of materials (Cullity 1978) including polymers, salts and complexes. In the present study, the XRD method has been used only in a limited perspective to identify or confirm the following: (i) amorphous, crystalline or semicrystalline nature of the material and (ii) complex formation.

The XRD pattern of pure PVC, PEO, $\mathrm{LiX}\left(\mathrm{X}=\mathrm{ClO}_{4}^{-}\right.$, $\mathrm{BF}_{4}^{-}$and $\mathrm{CF}_{3} \mathrm{SO}_{3}^{-}$) is shown in figure 1. The amorphous phase of PVC is evident from figure 1a. The XRD pattern of PEO manifests two distinct crystalline peaks (Such et al 1989) at $19.7^{\circ}$ and $23.9^{\circ}$ (figure $1 \mathrm{~b}$ ). The peaks pertaining to PEO are found with reduced intensities in the complexes, which could be due to the complexation of PEO with polymer PVC and salt LiX. The crystalline peaks pertaining to pure $\mathrm{LiClO}_{4}, \mathrm{LiBF}_{4}$ and $\mathrm{LiCF}_{3} \mathrm{SO}_{3}$ (figures $1 \mathrm{c}-\mathrm{e}$ ) are found to be absent in the complex figures $1 \mathrm{f}-\mathrm{h}$, indicating the complete dissolution of the salt in the polymer matrix, which is in accordance with the statement that complexation between the salts and polymer takes place in the amorphous region (Carre et al 1988), hence the confirmation of complexation.

\subsection{FTIR spectroscopic studies}

FTIR spectroscopy is important for the investigation of polymer structure. FTIR spectra of these materials vary according to their compositions and may be able to show the occurrence of complexation (Alamgir and Abhram 1994) and interactions between the various constituents. In the present work, FTIR spectroscopy is used to establish interactions between the polymers (PVC and PEO) and salts $\left(\mathrm{LiClO}_{4}, \mathrm{LiBF}_{4}\right.$ and $\left.\mathrm{LiCF}_{3} \mathrm{SO}_{3}\right)$, which can make changes in the vibrational modes of the atoms or molecules in the materials.

FTIR spectra of pure PVC, PEO, $\mathrm{LiClO}_{4}, \mathrm{LiBF}_{4}$, $\mathrm{LiCF}_{3} \mathrm{SO}_{3}$ and complexes are shown in figure 2. The bands at 1333,1254 and $950 \mathrm{~cm}^{-1}$ in pure PVC are assigned to $\mathrm{CH}_{2}$ deformation, $\mathrm{CH}$ rocking and $\mathrm{CH}$ wagging respectively. The bands at 2900, 1950 and $1430 \mathrm{~cm}^{-1}$ in 
pure $\mathrm{PEO}$ are assigned to $\mathrm{CH}$ symmetrical stretching, asymmetric stretching and asymmetric bending vibration, respectively. The absorption peaks appearing at $1450 \mathrm{~cm}^{-1}$ in pure PEO is shifted to a higher frequency region in the complexes. The absorption peak at $1333 \mathrm{~cm}^{-1}$ in pure PVC is shifted to $1342 \mathrm{~cm}^{-1}$ in all the complexes irrespective of the type of lithium salt added. The characteristic frequency of PVC at $1254 \mathrm{~cm}^{-1}$ is found be shifted around $1244 \mathrm{~cm}^{-1}$ in all the complexes. The trans $\mathrm{CH}$ wagging of PVC is shifted from $956 \mathrm{~cm}^{-1}$ to $946 \mathrm{~cm}^{-1}$.

The vibrational peaks appearing at 2741, 2559, 1435, 1199 and $890 \mathrm{~cm}^{-1}$ of PVC and the peaks 2900, 1600, $1325,1255 \mathrm{~cm}^{-1}$ of $\mathrm{PEO}$, are found to be absent in the polymer complexes. The frequencies of pure $\mathrm{LiCF}_{3} \mathrm{SO}_{3}$ (3477, 1639 and $\left.1084 \mathrm{~cm}^{-1}\right), \mathrm{LiClO}_{4}\left(1070\right.$ and $\left.626 \mathrm{~cm}^{-1}\right)$ and $\mathrm{LiBF}_{4}\left(1450 \mathrm{~cm}^{-1}\right)$ are shifted to $(3465,1638,1079$ $\left.\mathrm{cm}^{-1}\right),\left(1080\right.$ and $\left.614 \mathrm{~cm}^{-1}\right)$ and $\left(1466 \mathrm{~cm}^{-1}\right)$ in polymer complexes respectively. This may be due to the change in environment for the $\mathrm{CF}_{3} \mathrm{SO}_{3}^{-}, \mathrm{BF}_{4}^{-}$and $\mathrm{ClO}_{4}^{-}$ions in the complexes.

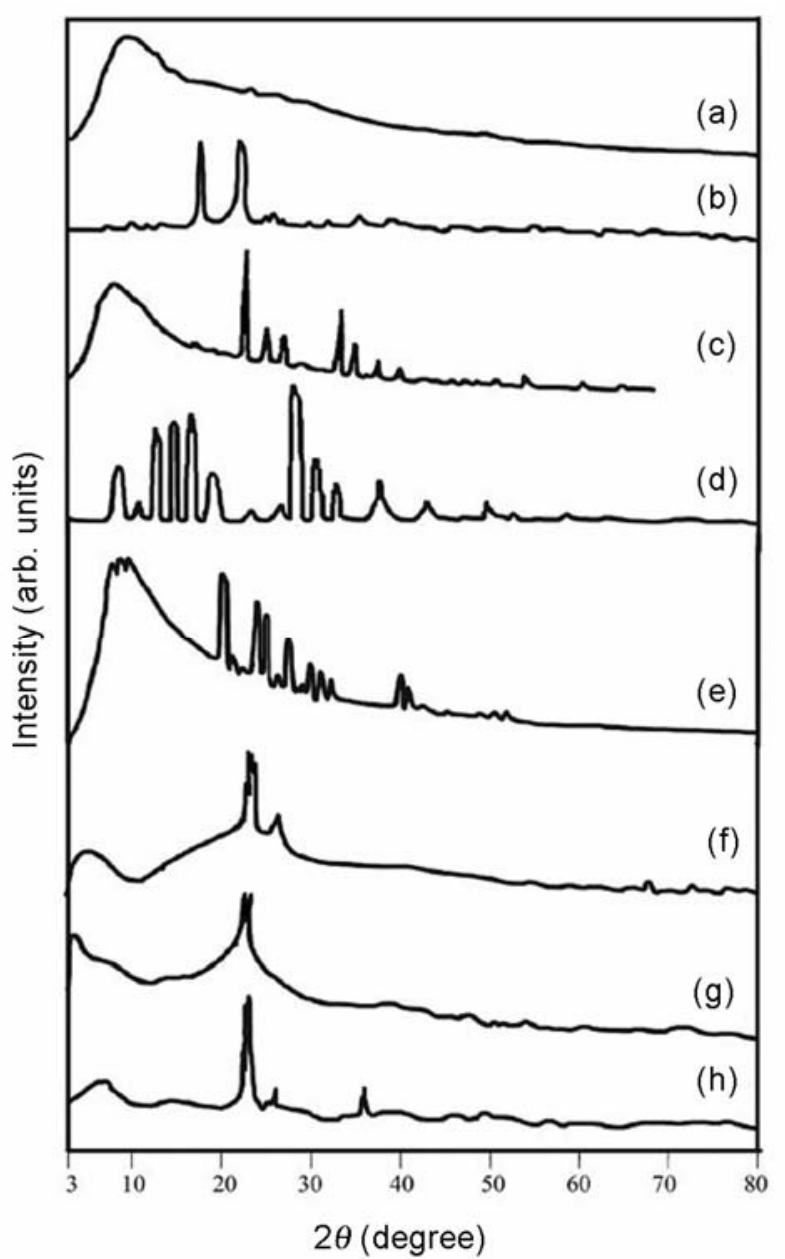

Figure 1. XRD patterns of pure (a) PVC, (b) PEO, (c) $\mathrm{LiClO}_{4}$, (d) $\mathrm{LiBF}_{4}$, (e) $\mathrm{LiCF}_{3} \mathrm{SO}_{3}$, (f) PVC-PEO-LiClO (g) PVC-PEO-LiBF 4 and (h) PVC-PEO-LiCF $\mathrm{SO}_{3}$.
In addition to the above, there are some new peaks obtained at around 3458, 2878, 1078 and $841 \mathrm{~cm}^{-1}$ in the complexes. The above analysis as a whole establishes the formation of polymer-salt complexes (Vien et al 1991).

\subsection{Conductivity measurements}

The ionic conductivity of a polymer electrolyte depends on (i) the actual concentration of the conducting species and (ii) their mobility. The low ionic conductivity in a polymer complex results from the crystalline phase that affects the mobility of ions. In the present work, blended polymer electrolytes were prepared using polymers PVC, $\mathrm{PEO}$ and different inorganic lithium salts such as $\mathrm{LiClO}_{4}$, $\mathrm{LiBF}_{4}$ and $\mathrm{LiCF}_{3} \mathrm{SO}_{3}$, employing solvent casting technique.

Polymer electrolytes with fixed ratios of polymers and salt [PVC(23)-PEO(69)-LiX(8); ( $\left.\mathrm{X}=\mathrm{ClO}_{4}^{-}, \mathrm{BF}_{4}^{-}, \mathrm{CF}_{3} \mathrm{SO}_{3}^{-}\right)$] were prepared in order to find the appropriate salt suitable to be competent in lithium battery applications. The polymer electrolyte films prepared were found to be translucent and free-standing. The ionic conductivity measurements have been carried out on these polymer

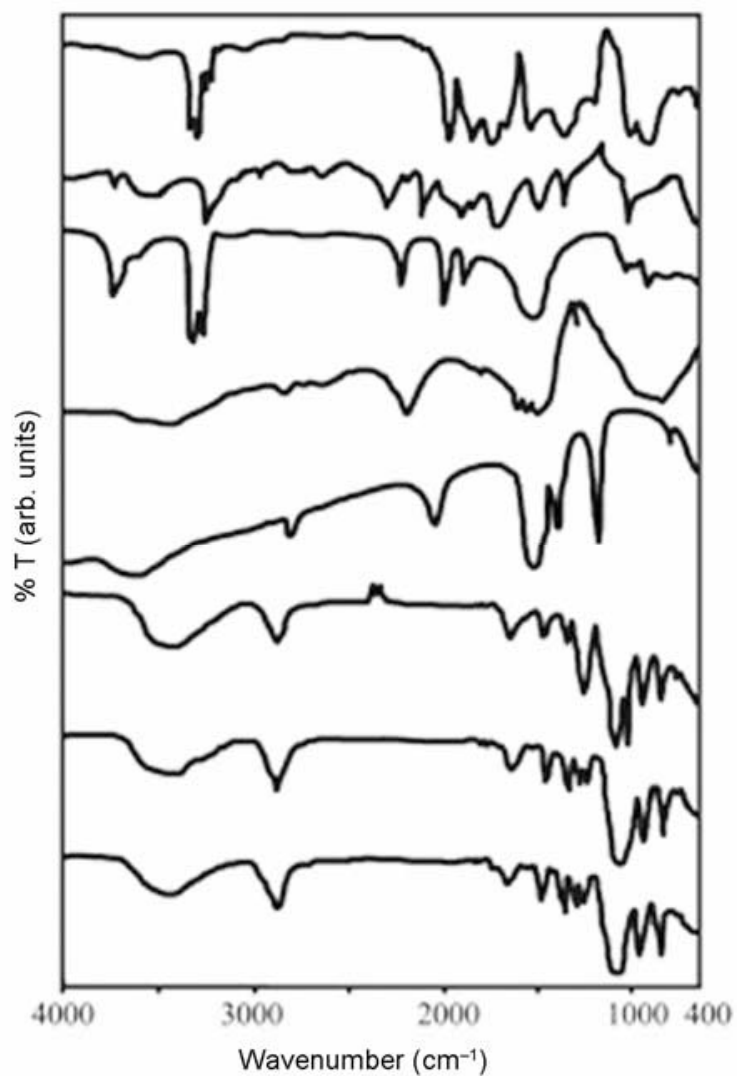

Figure 2. FTIR spectra of pure (a) PVC, (b) PEO, (c) $\mathrm{LiClO}_{4}$, (d) $\mathrm{LiBF}_{4}$, (e) $\mathrm{LiCF}_{3} \mathrm{SO}_{3}$, (f) $\mathrm{PVC}-\mathrm{PEO}-\mathrm{LiClO}_{4}$, (g) $\mathrm{PVC}-$ PEO-LiBF 4 and (h) PVC-PEO-LiCF $\mathrm{SO}_{3}$. 
Table 1. Conductivity values of PVC-PEO-LiX $\left(\mathrm{X}=\mathrm{ClO}_{4}, \mathrm{BF}_{4}, \mathrm{CF}_{3} \mathrm{SO}_{3}\right)$ at different temperatures.

\begin{tabular}{lccccc}
\hline & $\begin{array}{c}\text { Composition } \\
\text { PVC-PEO-LiX } \\
\text { Films }\end{array}$ & \multicolumn{4}{c}{ Conductivity values of PVC-PEO-LiX in $10^{-4} \mathrm{~S} \mathrm{~cm}^{-1}$} \\
\cline { 3 - 6 } & $(23-69-8)$ & $302 \mathrm{~K}$ & $318 \mathrm{~K}$ & $333 \mathrm{~K}$ & $353 \mathrm{~K}$ \\
\hline $\mathrm{U}_{1}$ & $\mathrm{LiClO}_{4}$ & 0.024 & 0.079 & 1.782 & 4.459 \\
$\mathrm{U}_{2}$ & $\mathrm{LiBF}_{4}$ & 0.079 & 0.316 & 7.249 & 26.300 \\
$\mathrm{U}_{3}$ & $\mathrm{LiCF}_{3} \mathrm{SO}_{3}$ & 0.009 & 0.018 & 0.226 & 0.891 \\
\hline
\end{tabular}

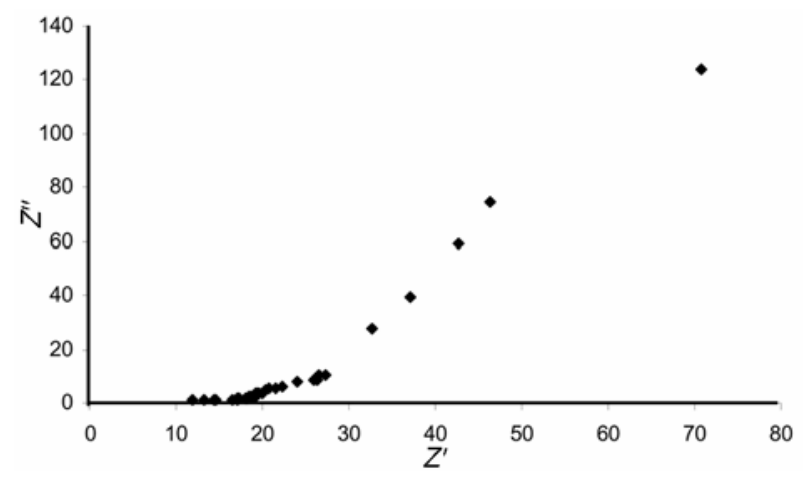

Figure 3. $Z$ real vs $Z$ imaginary plot for $\mathrm{PVC}: \mathrm{PEO}: \mathrm{LiBF}_{4}$ at room temperature.

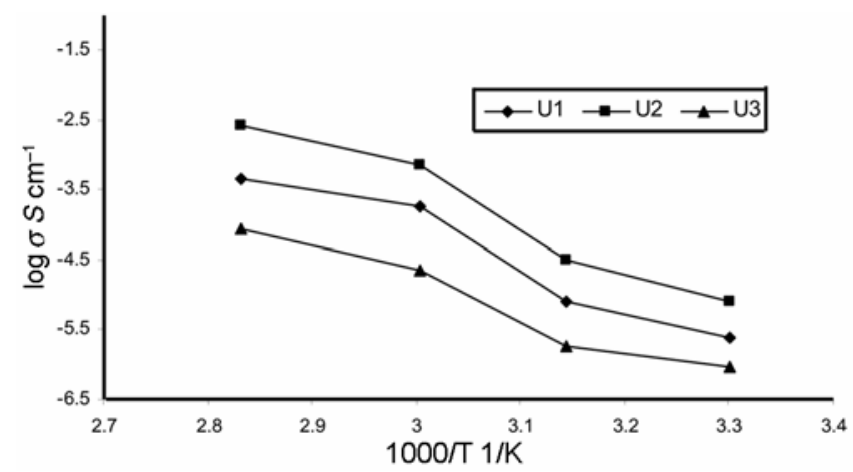

Figure 4. Arrhenius plot of $\log \sigma$ against reciprocal temperature of PVC: $\mathrm{PEO}$ : $\mathrm{LiX}\left(\mathrm{X}=\mathrm{ClO}_{4}^{-}, \mathrm{BF}_{4}^{-}\right.$and $\left.\mathrm{CF}_{3} \mathrm{SO}_{3}^{-}\right]$.

electrolytes by employing variable frequency complex a.c. impedance technique. The thin films of polymer complex were sandwiched between the two stainless steel electrodes attached to the conductivity jig specially designed for the ionic conductivity measurements. The two SS electrodes act as blocking electrodes for $\mathrm{Li}^{+}$ions under an applied electric field.

The conductivity of the polymer electrolyte was calculated from the measured resistance (obtained from ColeCole plot) for the known area ' $\mathrm{A}$ ' and thickness of the polymer film 'l', using the relation $\sigma=1 / R_{\mathrm{b}} A$, where $R_{\mathrm{b}}$ is the bulk resistance. Table 1 shows the conductivity values of the complex in the temperature range $303 \mathrm{~K}$ to $333 \mathrm{~K}$. The impedance isotherm for the PVC-PEO-LiBF (film $\mathrm{U}_{2}$ ) at room temperature is shown in figure 3 . The disappearance of high-frequency semicircular portion in the impedance curve leads to a conclusion that the current carriers are ions, and this leads one to further conclude that the total conductivity is mainly the result of ion conduction (Izuchi et al 1987). At low frequency, the complex impedance plot must show a straight line parallel to the imaginary axis, but the double layer at the blocking electrodes causes the curvature (Kim et al 1999).

In order to examine the temperature dependence of ionic conductivity, PVC-PEO-LiX films were subjected to conductivity measurements at four different temperatures viz. $30,45,60$ and $80^{\circ} \mathrm{C}$. It is evident that as the temperature increases (table 1 and figure 4) the conductivity is also found to increase. This behaviour could be explained on the basis of free volume model. At higher temperatures, thermal movement of polymer chain segments and the dissociation of the salts are improved, thereby increasing ionic conductivity. However, at low temperature the presence of lithium salt leads to saltpolymer or cation-dipole interactions, which increases the cohesive energy of polymer networks. As the free volume decreases, polymer segmental motion and ionic mobility are restricted, hence ionic conductivity decreases. This is in agreement with the theory.

The conductivity value of the film $\mathrm{U}_{2}$ [PVC(23)$\left.\mathrm{PEO}(69)-\mathrm{LiBF}_{4}(8)\right]$ is found to be $0.079 \times 10^{-4} \mathrm{~S} \mathrm{~cm}^{-1}$, which is indeed a higher value when compared to the other films that consist of $\mathrm{LiClO}_{4}$ and $\mathrm{LiCF}_{3} \mathrm{SO}_{3}$. This may be due to the reason that a smaller conductivity enhancement factor that for the $\mathrm{LiCF}_{3} \mathrm{SO}_{3}$ salt can be attributed to the larger anionic radius of the ion, similar results was reported (Shodai et al 1994). The degree of dissociation of the various lithium salts has been previously compared, and it was reported that the association tendency of the anions with $\mathrm{Li}^{+}$ions in non-aqueous aprotic solvents increases in the following order

$$
\mathrm{ClO}_{4}^{-}<\mathrm{BF}_{4}^{-}<\mathrm{CF}_{3} \mathrm{SO}_{3}^{-} \text {. }
$$

This result suggest that ion pairing takes place to a lesser extent in the electrolytes containing $\mathrm{LiClO}_{4}$ or $\mathrm{LiBF}_{4}$ compared with the electrolyte that contains $\mathrm{LiCF}_{3} \mathrm{SO}_{3}$.

\subsection{TG/DTA analysis}

In order to ascertain the thermal stability of the polymer electrolyte with maximum conductivity, the film was sub- 


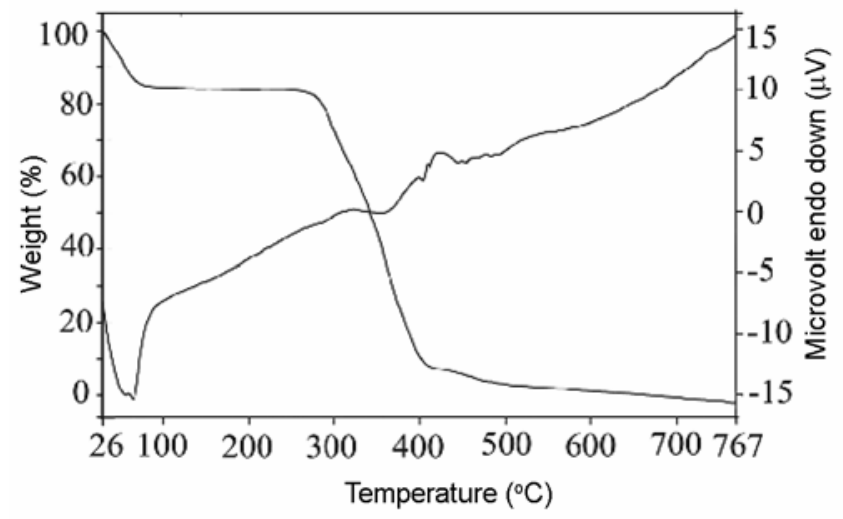

Figure 5. TG/DTA analysis of PVC-PEO-LiBF 4 .

jected to TG/DTA analysis in the range $25^{\circ} \mathrm{C}$ to $800^{\circ} \mathrm{C}$ at a heating rate of $10^{\circ} \mathrm{C} / \mathrm{min}$. The TG/DTA spectrum of the polymer electrolyte PVC-PEO-LiBF 4 is shown in figure 5. The TG curve shows a first degradation at $70^{\circ} \mathrm{C}$ accompanied by a weight loss of $14 \%$, which may be due to the evaporation of moisture absorbed by the sample during loading or the volatile impurities present (Scott and Macosko 1995; Stephen et al 2002). This first degradation is substantially asserted by the DTA curve giving an endothermic peak around $65-75^{\circ} \mathrm{C}$. The film is found stable from 70 to $276^{\circ} \mathrm{C}$, with a meager weight loss of $1 \%$, beyond $276^{\circ} \mathrm{C}$ the film looses its weight drastically up to $400^{\circ} \mathrm{C}$. This could be attributed to the decomposition of the polymer electrolyte. This result is found consistent with the DTA result. These results indicate that the samples are stable up to $276^{\circ} \mathrm{C}$. Since the polymer electrolyte maintains its stability in the range $70^{\circ} \mathrm{C}$ to $276^{\circ} \mathrm{C}$ with very meager weight loss, this indicates the evaporation/deterioration of polymers in the polymer electrolyte is absent. Hence, it is concluded that the polymer electrolyte is stable up to $276^{\circ} \mathrm{C}$.

\section{Conclusions}

Three different electrolyte systems consisting of PVCPEO-LiX $\left(\mathrm{X}=\mathrm{ClO}_{4}^{-}, \mathrm{BF}_{4}^{-}, \mathrm{CF}_{3} \mathrm{SO}_{3}^{-}\right]$have been studied. Among the three films, (film $\mathrm{U}_{2}$ ) the film with $\mathrm{LiBF}_{4}$ is found to be the best on the basis of conductivity. The conductivity of the polymer electrolyte PVC-PEO- $\mathrm{LiBF}_{4}$ is found to be $0.079 \times 10^{-4} \mathrm{~S} \mathrm{~cm}^{-1}$, and the film has a thermal stability up to $276^{\circ} \mathrm{C}$. Hence, the properties of PVCPEO- $\mathrm{LiBF}_{4}$ polymer electrolyte look very desirable and promising for lithium battery applications.

\section{References}

Abraham K M and Alamgir M 1991 Chem. Mater. 3339 Abraham K M 1993 Application of electroactive polymers (ed.) B Scrosati (London: Chapman and Hall) Ch. 3

Alamgir M and Abraham KM 1994 Lithium batteries, new materials, development and perspectives (ed.) G Pistoia (New York: Elsevier) Vol. 5
Scrosati B (ed.) 1993 Application of electroactive polymers (London: Chapman and Hall)

Appetecchi G B, Croce F and Scrosati B 1995 Electrochim. Acta 40991

Armand M B 1979 Fast ion transport in solids (ed.) P Vashista (Amsterdam: Elsevier)

Balleard D G H, Cheshire P, Mann T S and Przeworski J E 1990 Macromolecules 231256

Borkowska R, Plocharski J, Laskowski J, Wieczorek W and Przyluski J 1993 J. Appl. Electrochem. 23991

Bruce P 1995 Solid state electrochemistry (Cambridge: Cambridge University Press)

Capuano F, Croce F and Scrosati B 1991 J. Electrochem. Soc. 1381918

Capiglia C, Yang J, Imanishi N, Hirano A, Takeda T and Yamamoto O 2002 Solid State Ionics 154-155 393

Carre C, Hamaide T, Guyot A and Mai C 1988 Br. Polym. J. 20269

Cheradame H and Lee Nest J F 1987 Polymer electrolytes reviews (eds) J R MacCallum and $\mathrm{C} A$ Vincent (London: Elsevier) Vol. 1, Ch. 5

Croce F, Appetecchi G B, Persi L and Scrosati B 1998 Nature 39445

Croce F, Capuano F, Selvaggi A and Scrosati B 1990 J. Power Sources 32389

Cullity B D 1978 Elements of X-ray diffraction (Addison Wiley) 2nd edn

Dobrowski S A, Davies G R, McIntyre J E and Ward I M 1991 Polymer 3229887

Fautex D 1988 J. Electrochem. Soc. 1352231

Fenton B E, Parker J M and Wright P V 1973 Polymer 458

Gray F M 1991 Solid polymer electrolytes-fundamentals and technological applications (Germany, $\mathrm{VCH}$, Weinheim)

Huang B, Wang Z, Li G, Huang H, Xue R, Chen L and Wang F 1996 Solid State Ionics 8579

Inganas O 1988 Br. Polym. J. 20233

Itoh T, Hirata N, Wen Z, Kubo M and Yamamoto O 2001 J. Power Sources 97-98 637

Izuchi S, Ochiai S and Takeuchi K 1987 J. Power Sources 6837

Kelly IE, Owens J R and Steele B C H 1984 Electroanal. Chem. 168467

Kim C, Lee G, Lio K, Ryu K S, Kang S G and Chang S H 1999 Solid State Ionics 123251

MacCallum J R and Vincent C A (eds) 1987 Polymer electrolytes reviews (London: Elsevier) Vol 1

Rajendran S, Ravi Shanker Babu and Kanimozhi K 2007 Indian J. Phys. 811

Scott C E and Macosko C W 1995 Polymer 36461

Scrosati B 1987 In Polymer electrolytes reviews (eds) J R MacCallum and C A Vincent (London: Elsevier) Vol. 1, Ch. 4

Scrosati B and Neat R J 1993 Application of electroactive polymers (ed.) B Scrosati (London: Chapman and Hall) Ch. 6

Shodai T, Owens B B, Suke Oh and Yamakai J 1994 J. Electrochem. Soc. 1412978

Stephen A M, Saito Y, Muniyandi N, Ranganathan N G, Kalyanasundaram S and Nimma Elizabeth R 2002 Solid State Ionics 148467

Such K, Florianczky Z, Weiczorek W and Przyluski J 1989 Second International symposium on polymer electrolytes, p. 9 
Sun H Y, Takeda Y, Imanishi N, Yamamoto O and Sohn H -J 2000 J. Electrochem. Soc. 1472462

Takeuchi T, Capigilia C, Balakrishnan N, Takeda Y and Kageyama H 2002 J. Mater. Res. 17575

Vincent C A 1987 Prog. Solid State Chem. 17145
Vien D L, Colthup N B, Faleley W G and Grasseli J G 1991 Infrared and Raman characteristic frequencies of organic molecules (New York: Academic Press) p. 85

Wen Z, Itoh T, Ichikawa Y, Kubo M and Yamamoto O 2000 Solid State Ionics 134281 